\title{
O HORIZONTE TEMÁTICO-VALORATIVO EM FÓRUNS ONLINE NA FORMAÇÃO DE PROFESSORES DE LÍNGUA PORTUGUESA: UMA ANÁLISE DIALÓGICA
}

\author{
THE TEMATIC-VALUE HORIZON IN ONLINE FORUMS IN \\ PORTUGUESE LANGUAGE TEACHER EDUCATION: A DIALOGAL ANALYSIS
}

Inglyde Jeane da Silva Vieira ${ }^{1}$ Lattes | inglydejeane@hotmail.com
Universidade Tecnológica Federal do Paraná

Nívea Rohling² | Lattes | nivear@utfpr.edu.br

Universidade Tecnológica Federal do Paraná

Resumo: Este artigo apresenta uma análise de interações interlocutivas em fóruns de discussão, inseridos no ambiente de formação continuada de professores de Língua Portuguesa em um Portal Educacional. Buscou-se compreender os sentidos produzidos a partir do horizonte temático-valorativo dessas interações interlocutivas em situação de formação continuada de professores em um ambiente online. A investigação baseou-se nos pressupostos teórico-metodológicos da Perspectiva Dialógica de Linguagem, elaborada pelo Círculo de Bakhtin (BAKHTIN, 2003 [1979]; 2008 [1963]; 2016 [1953]). Foram analisados enunciados produzidos em três fóruns produzidos nos períodos de maio e setembro de 2012 e maio de 2013. A análise aponta para uma acentuação conteudista dos temas em pauta na formação, bem como uma valoração mais proeminente dos materiais disponibilizados e da demanda oficial em detrimento aos posicionamentos dos professores advindos de seus saberes constituídos na prática educativa.

Palavras-chave: Formação continuada de professores de Língua Portuguesa. Dialogismo. Horizonte temático-valorativo.

\footnotetext{
1 Mestre pelo Programa de Pós-Graduação em Estudos de Linguagens (PPGEL) na área de Concentração "Linguagem e Tecnologia", na linha de pesquisa "Multiletramentos, discurso e processos de produção de sentido”, da Universidade Tecnológica Federal do Paraná (UTFPR), Curitiba - PR.

2 Docente do Departamento Acadêmico de Linguagem e Comunicação da Universidade Tecnológica Federal do Paraná (UTFPR), no Programa de Pós-Graduação em Estudos de Linguagens (PPGEL), Curitiba PR.
} 
Abstract: This paper presents an analysis of interlocutive interactions in discussion forums, inserted in Portuguese Language teacher continued education environment in an Educational Portal. We sought to understand the meanings produced from the thematic-value horizon in these interlocutive interactions in an online continued teacher education in environment. The research was based on the Dialogical Perspective of Language as the theoretical-methodological assumptions elaborated by the Bakhtin Circle. Statements produced in three forums between May and September 2012 and on May 2013 were analyzed. The analysis points to focurs on content in educaation themes, as well as a more prominent valuation of available materials and official demands. in detriment of teachers' positions arising from their knowledge in the educational practice.

Keywords: Teacher training. Continued Portuguese Language teacher training. . Dialogism. Tematic-value horizon.

\section{INTRODUÇÃO}

O conhecimento construído no âmbito profissional, em qualquer área de atuação, representa a gama de saberes concebida pelo indivíduo para o exercício de sua profissão. Isso corresponde ao que Tardif (2002) denomina, no âmbito da formação docente, como saberes profissionais.

No âmbito da formação do professor, a formação (inicial e continuada) é resultante desse conhecimento construído paulatinamente. Segundo Gatinho (2006), os saberes profissionais dos professores, além de serem plurais, heterogêneos e históricos, são constituídos a partir de diferentes fontes, não são unificados e são adquiridos ao longo do tempo, ou seja, são personalizados e situados.

Pesquisas recentes em Linguística Aplicada destacam os desafios da sociedade de responder a uma constante preocupação com os currículos e o processo de ensino-aprendizagem, apontando para um "discurso da atualização e da necessidade de renovação" (GATTI, 2008, p. 58). De acordo com Gatti (2008), nos últimos anos do século XX, tornou-se forte, nos mais variados setores profissionais e nos setores universitários, a questão da imperiosidade de formação continuada como um requisito para o trabalho docente. Isso tem relação com a ideia da atualização constante, em função das mudanças nos conhecimentos e nas tecnologias e das mudanças no mundo do trabalho.

Segundo a autora,

[...] a educação continuada foi colocada como aprofundamento e avanço nas formações dos profissionais. Incorporou-se essa necessidade também 
aos setores profissionais da educação, o que exigiu o desenvolvimento de políticas nacionais ou regionais em resposta a problemas característicos de nosso sistema educacional. (GATTI, 2008, p. 58).

Após os anos 1990, a formação continuada de professores, por meio das ideias de atualização, reciclagem e outras exigências, continuou a ter bastante influência nas discussões, pesquisas e debates sobre a atuação do professor e a mover políticas educacionais de incentivo. Assim, a partir de problemas concretos da educação, deu-se início às "chamadas de educação continuada, especialmente na área pública, pela constatação de que os cursos de formação básica dos professores não vinham (e não vêm) propiciando adequada base para sua atuação profissional” (GATTI, 2008, p. 58). Desde então, diversos projetos e programas foram e são criados constantemente, tanto de iniciativa pública, quanto no setor privado.

No conjunto de pesquisas e debates envolvendo a formação continuada, vem se discutindo também projetos que levem em conta a inserção das novas tecnologias ${ }^{3}$, e por isso emergem contemporaneamente formações continuadas em espaços mediados por tecnologias digitais. Conforme Gonçalves e Petroni (2012, p. 7), "no quadro geral da educação brasileira [...] é preciso acompanhar o desenvolvimento de uma sociedade cada vez mais informatizada e exigente de múltiplos letramentos”. Despontam, nesse cenário, novos espaços para essa formação: os ambientes online e a necessidade de analisar dentro desses ambientes o contexto de formação continuada como "espaços híbridos voltados para as demandas da educação" (ROJO, 2013, p. 190).

Nesse sentido, há uma considerável mudança nos modos de realizar a formação inicial e continuada do professor, que têm se dado, em parte, em espaços interacionais mediados pelos ambientes online 4 , como exemplo, fóruns de discussão inseridos em portais educacionais, cursos de curta duração na modalidade de Educação a Distância, mediados por ambientes de aprendizagem online, dentre outros.

\footnotetext{
${ }^{3}$ Em consonância com as ideias de Barton e Lee (2015), entende-se por novas tecnologias os espaços em redes sociais que têm mediado todos os contextos da vida contemporânea. Assim, mudanças em todos os domínios da vida (trabalho, vida cotidiana, ambiente escolar etc.) têm ocorrido, dada a emergência das novas tecnologias de informação e comunicação. Essa realidade tem alterado o modo das relações sociais mais amplas "e isso impacta a linguagem e as práticas comunicativas" (BARTON; LEE, 2015, p. 12). No contexto da formação continuada, a partir das novas tecnologias, emerge um novo espaço mediador dessa modalidade de formação.

4 No período do fechamento desse artigo, por ocasião do distanciamento social em decorrência da Pandemia de COVID-19 no Brasil em março de 2020, está em evidência o ensino remoto emergencial. Esse momento aponta uma outra fase do uso de tecnologias em que as mediações para formação docente e ensino tem se dado por meio de ferramentas síncronas ou assíncronas mais recentes como vídeos e lives em redes sociais como Youtube, Instagram, dispensando o uso de Portais Educacionais. Essa convergência de mídias vem borrando as relações de espaços institucionais e espaços de entretenimento.
} 
Assim, as políticas educacionais passaram a direcionar o olhar para a formação continuada em outros contextos (geralmente oferecida pelas Secretarias de Educação). Nessa discussão, de acordo com Gatti,

\begin{abstract}
nos últimos anos, justificado até como uma forma mais rápida de prover formação, pois, pelas tecnologias disponíveis, pode-se flexibilizar os tempos formativos e os alunos teriam condições, quando se trata de trabalhadores, de, em algumas modalidades de oferta, estudar nas horas de que dispõem, não precisando ter horários fixos, o que permitiria compatibilização com diversos tipos de jornadas de trabalho. A educação a distância ou a mista (presencial/a distância) tem sido o caminho mais escolhido para a educação continuada de professores pelas políticas públicas, tanto em nível federal como estadual e municipal. (GATTI, 2008, p. 65).
\end{abstract}

Dessa forma, com vistas a observar um contexto de formação continuada que se dá em plataformas online, é que se desenvolveu a seguinte questão de pesquisa: Como se constituem as interações interlocutivas entre professores de Lingua Portuguesa e formadores, em contexto de formação continuada, mais especificamente em fóruns de discussão, em um Portal Educacional? A partir dessa questão de investigação, desenvolveu-se a presente análise realizada, recortando os aspectos relativos ao horizonte temático-valorativo dos enunciados produzidos no interior desses fóruns de discussão.

Para tanto, inicialmente apresentamos o quadro teórico mobilizado em torno dos conceitos tema, significação e horizonte valorativo, elaborados pelo Círculo de Bakhtin (BAKHTIN, 2003 [1979]; 2008 [1963]; 2016 [1953]). A seguir, fazemos uma descrição do Portal Educacional em que os fóruns foram gerados e uma descrição dos dados. Por fim, apresentamos a análise dos fóruns, delimitados para essa discussão.

\title{
O HORIZONTE TEMÁTICO-VALORATIVO DOS ENUNCIADOS NA PERSPECTIVA DIALÓGICA
}

Na perspectiva do Círculo de Bakhtin, o aspecto temático relaciona o enunciado à sua dimensão social, ao seu objeto do discurso, e representa o nível de conhecimento que os interlocutores possuem da situação de interação. Em outros termos, trata-se do conhecimento e da compreensão comum da situação de interação por parte dos interlocutores e relaciona-se ao objeto de discurso e sentidos produzidos.

No capítulo de Marxismo e Filosofia da Linguagem, intitulado Tema e significação na língua, Bakhtin e Volochínov falam sobre o horizonte temático como o sentido único de uma enunciação. Nas palavras dos autores, 
O tema deve ser único. Caso contrário, não teríamos nenhuma base para definir a enunciação. O tema da enunciação é na verdade, assim como a própria enunciação, individual e não reiterável. Ele se apresenta como a expressão de uma situação histórica concreta que deu origem à enunciação. (BAKHTIN; VOLOCHÍNOV, 2006 [1929], p. 131).

O tema é algo constitutivo de todo enunciado, assim como o estilo e a composição. Conforme Rodrigues (2005), cada situação interlocutiva é determinada pelo seu conteúdo temático, e, assim, todo gênero tem um conteúdo temático determinado: seu objetivo discursivo e finalidade discursiva, sua orientação de sentido específica para com ele e os outros participantes da interação discursiva (RODRIGUES, 2005).

O horizonte temático "de um gênero também se orienta pelos sentidos, que são outros enunciados, o que nos remete à questão das relações dialógicas" (ROHLING DA SILVA, 2012, p. 36). Essas relações dialógicas com outros enunciados acontecem, uma vez que, para Bakhtin, "cada enunciado é pleno de ecos e ressonâncias de outros enunciados com os quais está ligado pela identidade da esfera de comunicação discursiva” (BAKHTIN, 2003 [1979], p. 297).

No entanto, ao mesmo tempo em que cada enunciado apresenta esses ecos e ressonâncias do discurso alheio é também constituído de algo singular. Segundo Bakhtin, "as palavras do outro na nossa fala são revestidas inevitavelmente de algo novo, da nossa compreensão e da nossa avaliação, isto é, tornam-se bivocais" (BAKHTIN, 2008 [1963], p. 223). A partir desse movimento do discurso bivocal, essas tomam um sentido divergente, "passam a variar acentuadamente, o discurso orientado para um único fim pode converter-se em discurso orientado para diversos fins, a dialogação interna pode intensificar-se ou atenuar-se [...]” (BAKHTIN, 2008 [1963], p. 228).

Tecendo uma interpretação das palavras do autor, nesse sentido, é possível construir intenções diversas a partir do plano discursivo do outro, sem haver tensão entre as intenções do autor na voz do outro, uma vez que este estiliza e reveste de significação o discurso do outro para alcançar os objetivos pretendidos - e nisso consiste a dialogização interna.

A palavra do outro no discurso também pode ocorrer de forma explícita, como discurso citado, nomeado por Bakhtin como o enquadramento do discurso do outro, que se caracteriza "por conferir a esse discurso citado um novo acento de valor, criar um 'ângulo’ dialógico-axiológico que o autor pretende inserir nesse discurso" (ROHLING DA SILVA, 2007, p. 124). Sobre isso, Rodrigues (2005) pondera que as formas e os graus da 
orientação dialógica com relação aos discursos alheios se manifestam de maneira variada nos diferentes gêneros do discurso em circulação social. A palavra do outro pode ser um elemento indispensável, um argumento de autoridade, que se destaca explicitamente em muitos gêneros. Mas, em outros, essa relação pode se manifestar de forma mais difusa, aparecendo em determinados aspectos do estilo e da composição. A orientação específica (suas formas e graus) para a palavra do outro nos gêneros está ligada a singularidades das diferentes esferas. Em muitos gêneros - nos gêneros literários, por exemplo -, há um tratamento mais livre da palavra, do enunciado do outro. Já nos gêneros judiciais e científicos, por exemplo, há um maior senso de propriedade do discurso do outro, bem como da sua posição, do seu valor social, revelando-se nas formas da sua citação.

Uma outra questão que envolve o tema do enunciado é o juízo de valor imbricado neste em virtude da natureza ideológica da linguagem. De acordo com Bakhtin e Volochínov (2006 [1929], p. 44), "não pode entrar no domínio da ideologia, tomar forma e aí deitar raízes senão aquilo que adquiriu um valor social”. Os índices valorativos/ axiológicos são saturados por ideologias e se constituem nas diversas situações de interação social e, portanto, são de natureza interindividual.

De acordo com Rodrigues (2005), o horizonte valorativo de um enunciado também se vincula ao auditório social, uma vez que, ao enunciar, o locutor, junto com este auditório, constrói o grupo, o meio social, ou as diversas condições socioeconômicas essenciais para a dinâmica e articulação deste grupo em sua rede de relações interpessoais, agindo sobre os sentidos e sobre as significações interindividuais, bem como formando signos e os saturando de recortes valorativos e de orientações ideológicas. Para Rodrigues, a noção de enunciado veicula uma significação objetiva e social e corresponde aos valores ideológicos de um determinado grupo social, situado em um determinado tempo e espaço, sendo, pois, um índice intersubjetivo de valor socioideológico. A dependência do enunciado em relação ao peso sócio-hierárquico do auditório, junto com a situação específica, é o espaço da elaboração da orientação social valorativa, presente em qualquer enunciado, de modo que a mudança de situação e de auditório altera a orientação social valorativa do enunciado e, consequentemente, o seu sentido. A avaliação social é um elemento fundamental, ou melhor, indispensável, para a construção de qualquer enunciado. É ela que lhe dá “vida”, situando-o num determinado lugar social (RODRIGUES, 2005).

Bakhtin e Volochínov (2006 [1929]) definem ainda o horizonte valorativo relacionado às classes sociais que compreendem às refrações do signo ideológico, à luta de classes. Para o autor, "em todo signo ideológico confrontam-se índices de valor con- 
traditórios. O signo se torna a arena onde se desenvolve a luta de classes" (BAKHTIN; VOLOCHÍNOV, 2006 [1929], p. 45). Nesse sentido, é justamente esse entrecruzamento dos índices de valor que tornam o signo vivo e móvel, capaz de evoluir e que é tomado como arena discursiva, dado o confronto dos valores sociais vivos.

Até aqui, apresentamos conceitos importantes para o olhar sobre o nosso objeto de investigação. Na seção a seguir, descrevemos o objeto de análise.

\section{FÓRUNS ONLINE DE DISCUSSÃO: O ESPAÇO MAIS IMEDIATO DAS INTERAÇÕES INTERLOCUTIVAS}

Em termos mais amplos, uma plataforma online pode ser considerada como um suporte (uma vez que comporta diversas atividades e gêneros discursivos) e, ao mesmo tempo, como uma entidade multimodal, pois a "multimodalidade está cada vez mais presente na construção de significados, e significados criados através do texto escrito fazem parte de um pacote que engloba outras modalidades de linguagem, como imagem e som" (ROJO, 2013, p.195).

De acordo com Furtado (2004), é preciso considerar que existem dois tipos de portais. Os horizontais, que no Brasil são os mais acessados em decorrência da abrangência de temáticas, o que resulta em um maior número de internautas (UOL, Globo.com, Terra, dentre outros); e os verticais, que possuem uma temática específica e, consequentemente, um público definido, como é o caso do Portal Educacional em foco neste estudo.

Uma das características principais dos portais verticais é que estes buscam discutir de forma abrangente a temática definida "oferecendo o maior número possível de informações, reunindo especialistas, agrupando comunidades, prestando muitas vezes consultorias e serviços adicionais" (FURTADO, 2004, p. 51). Ainda, de acordo com o autor, o portal vertical foi o modelo escolhido para abordar a temática da educação no Brasil e o seu surgimento data de 2004, sendo explorado por comércios de educação privada, ONGs educacionais, e por órgãos governamentais.

Os fóruns online que utilizamos como foco desta análise foram gerados no interior de uma formação de professores de Língua Portuguesa em um Portal Educacional, criada e mantida por uma Secretaria de Educação Estadual no sul do Brasil. Em uma perspectiva dialógica, podemos considerar um fórum no contexto educacional como gênero secundário (BAKHTIN, 2016 [1953]), uma vez que surge em meio a situações de uso da língua mais complexas e requer um maior monitoramento e formalidade, dada a necessidade de uso da modalidade escrita da língua, como também da intervenção de iniciativas públicas, privadas etc. Em termos gerais, o fórum online "está presente nos mais variados sítios, 
seja nos da esfera jornalística, em que materializa o debate de assuntos contemporâneos, seja na esfera do trabalho etc." (ROHLING DA SILVA, 2012, p. 83), e essa incidência de discussões em fóruns é emergente dada a flexibilidade em se discutir temas relevantes em tempo real em ambientes digitais.

Sobre a conceituação de fórum em contexto de $\mathrm{EaD}$, de acordo com Rohling da Silva (2012), o gênero fórum surge para cumprir objetivos pretendidos pela instituição proponente, ou seja, em virtude do contexto em que se insere e dos participantes, buscam-se soluções ou discussões sobre determinados temas. Eem outras palavras, os fóruns "tematizam os objetos discursivos propostos pela equipe responsável pela disciplina” (ROHLING DA SILVA, 2012, p. 82). Do ponto de vista da composição, ainda na concepção da autora, o fórum "se apresenta [...] pela troca de turnos e por uma relação discursiva bem marcada e delimitada pelo papel discursivo-autoral dos interlocutores em dada situação discursiva" (ROHLING DA SILVA, 2012, p. 83). Além disso, as interações nos fóruns podem se dar de forma mais ou menos monitorada.

Nas situações interlocutivas em que as interações são menos monitoradas, é permitido "aos interlocutores um acesso irrestrito às informações anteriormente postadas" (ROHLING DA SILVA, 2012, p. 83) e geralmente nessas situações os fóruns são direcionados a um público menor, mais restrito (é o caso dos cursos $\mathrm{EaD}$ direcionados a turmas específicas). Já em contextos em que são mais monitorados, há uma incidência maior de participantes, o que implica na escolha de uma ferramenta a ser monitorada por uma equipe (é o caso dos fóruns gerenciados pelas instâncias públicas de ensino que utilizam softwares de monitoramento em virtude da quantidade de participantes).

Outra característica relevante do fórum online é a similaridade com a mensagem instantânea (MI) (BARTON; LEE, 2015), no sentido estrutural, por diversos fatores tais como: é interativo ${ }^{5}$; é rico em texto gerado pelo usuário; suporta mensagens multimodais; promove novas formas de criatividade, bem como novas oportunidades de aprendizagem (BARTON; LEE, 2015). O fórum também apresenta, em comum com as MI, a data e o horário das postagens, remetendo à ideia de instantaneidade; nome ou indicação dos participantes e identificação dos tópicos (característica presente em alguns).

Para a presente análise, foram analisados enunciados produzidos em três fóruns online, intitulados: "Adaptações cinematográficas”; "HQs e clássicos literários" e "Internetês".

\footnotetext{
5 Em uma perspectiva dialógica, todo enunciado é interativo, precede de um enunciado anterior e requer uma resposta ativa, porém, no âmbito das mídias digitais, o termo 'interativo' parece referir-se a uma maior possibilidade de materialização dessa resposta ativa dos interlocutores em uma situação de interação específica.
} 
Que ocorreram nos períodos de maio e setembro de 2012 e maio de 2013. Esse recorte temporal compreende aos três únicos encontros semestrais da disciplina de Língua Portuguesa (LP) nos fóruns. Os interlocutores nesses enunciados são: professores de Língua Portuguesa da Rede Estadual de Educação do Paraná, sujeitos em formação continuada e profissionais da Secretaria de Educação e Diretoria de Tecnologia, considerada nesta investigação como Instância Formadora (IF).

Os três fóruns focalizados, neste estudo, apresentam as características inerentes a esse gênero, sendo, pois, um espaço em que os interlocutores tomam/ocupam os turnos com objetivo de debater/discutir determinado tema em pauta no grupo. Um aspecto bem recorrente nos fóruns é uso de hiperlinks para acesso aos materiais disponibilizados por uma equipe de professores técnicos da disciplina de LP, considerados neste estudo como formadores. Esses hiperlinks direcionam o participante do fórum, a saber os professores de LP, à página do recurso didático específico e há a opção de avaliar, comentar, indicar, alterar e informar erro. Tal recurso mostra-se como uma estratégia própria dos portais verticais para assegurar ao usuário todas as informações necessárias em um só lugar, a fim de que este não necessite navegar em outros espaços online fora do portal.

Assim, conforme já discutido, os hiperlinks direcionam o professor em formação ao acesso de recursos disponíveis, mostram-se presentes de modo saliente nas discussões e constroem as interações no modo de enunciar dos sujeitos, sobretudo nos fóruns "Adaptações cinematográficas" e "HQs e clássicos literários”, tendo em vista que as interações promovidas priorizavam a indicação dos materiais disponíveis.

Em outros termos, o recurso de indicar materiais por meio de hiperlink, na maior parte das vezes, foi utilizado pela instância oficial e por um número mínimo de professores. A IF, para fazer referência aos materiais ou tirar dúvidas, e alguns professores, para situar os demais interlocutores sobre a que assunto/recurso estava se referindo especificamente.

A seguir, apresentamos algumas interações em que a IF e os professores interagem indicando hiperlinks sobre os assuntos em pauta, por vezes indicando os recursos dos fóruns, e por outras indicando sites que não estão listados nos recursos dos fóruns, mas que incidem na troca de conhecimentos com os outros professores ${ }^{6}$.

\footnotetext{
6 Lembrando que essa incidência de uso de hiperlinks é típica dos fóruns "HQs e clássicos literários" e "Adaptações cinematográficas”. O fórum "internetês", diferentemente, apenas discute as concepções de língua, sem se ater especificamente aos links dos recursos disponíveis no fórum.
} 
C1 - IF - "HQs e clássicos literários"

Olá. O site da turma da Mônica é bem interessante. Outro http://www.nied.unicamp.br/ hagaque/ C2 - Emanuelle - "HQs e clássicos literários"

Existem, sites que proporcionam a criação de HQs e um dos recursos é inserir textos nos balões. Por exemplo: www.livrogame.com.br

Nesta seção, descrevemos, de modo geral, o Portal Educacional, bem como os fóruns de discussão. A seguir, apresentamos a análise mais focal do horizonte temático-valorativo dos enunciados.

\section{DOS SENTIDOS PRODUZIDOS: TEMA E VALORAÇÃO}

Ao tomar o enunciado como objeto de análise, é preciso considerar que todo enunciado, na perspectiva dialógica, é produzido em uma dada esfera de atividade humana e é direcionado a alguém (BAKHTIN, 2016 [1953]). As esferas de atividade humana são concebidas como campos de produção e circulação desses enunciados, ou seja, a partir da necessidade de uso da linguagem para determinados fins e em determinadas situações de interação discursiva.

Desse modo, cada interlocutor organiza seu projeto de dizer pressupondo um auditório social, em outros termos, um horizonte social, e assim há um interlocutor definido ou, pelo menos, em potencial (BAKHTIN; VOLOCHÍNOV, 2006 [1929], p. 17). Ao levar em conta esse horizonte social, cada sujeito direciona e define os seus posicionamentos em determinadas situações de interação. Assim, é a situação de interação na qual se inclui o auditório, que irá definir o que será verbalizado na interação como também os sentidos outros produzidos: posição, juízos de valor, esfera da comunicação verbal; e, quando verbalizado, irá pressupor uma resposta ou uma atitude responsiva do ouvinte (BAKHTIN; VOLOCHÍNOV, 2006 [1929]).

Assim, é possível dizer que os enunciados em tela, produzidos em fóruns online na situação de formação de professor de LP, pertencem à esfera escolar, uma vez que essas interações foram produzidas a fim de cumprir exigências com relação ao cumprimento de Horas de Atividade de Formação para professores de uma Rede Estadual de Ensino e estão em relação com a esfera governamental/oficial, promotora da referida formação. Quanto às funções enunciativas desempenhadas pelos interlocutores inseridos nos fóruns, estas são distintas. Em primeira instância, temos os professores de LP em formação

\footnotetext{
7 Com vistas à apresentação dos comentários, utilizamos $\mathrm{C}$ para enumerar os comentários, como também apresentamos um nome fictício para os interlocutores dos fóruns. Os fóruns estão disponíveis, de modo aberto, no Portal Dia Dia da Educação. Disponível em: https://www.portugues.seed.pr.gov.br/modules/ conteudo/. Acesso em 30/05/2020.
} 
continuada de uma Rede Pública Estadual de Ensino, que assumem nesse espaço o papel de cursistas - professores em formação - e cabe a eles debaterem os temas propostos pela equipe pedagógica, sendo esta a IF.

De acordo com Bakhtin e Volochínov (2006 [1929]), as interações interlocutivas são constituídas sócio e ideologicamente, por assim dizer "o tema ideológico possui sempre um índice de valor social. Por certo, todos estes índices sociais de valor dos temas ideológicos chegam igualmente à consciência individual que, como sabemos, é toda ideologia" (BAKHTIN; VOLOCHÍNOV, 2006 [1929], p. 44). O tema de um enunciado relaciona-se à dimensão social representando o nível de compreensão da situação por parte de todos os sujeitos imbricados na interação (ROHLING DA SILVA, 2012). O tema aponta ainda unicidade, uma vez que, assim como no enunciado, evidencia uma situação concreta e situada historicamente (BAKHTIN; VOLOCHÍNOV, 2006 [1929]) e, ao mesmo tempo, esse horizonte temático é determinado pelo seu estilo, composição, objeto e finalidade discursivos e conteúdo temático, tanto individualmente, quanto na relação com os outros na interação e com outros enunciados (ROHLING DA SILVA, 2012).

No que diz respeito ao tema, toda a arquitetura e a realização dos fóruns do portal não foram escolhidos de forma aleatória, houve um arranjo institucionalizado em virtude de aquela situação ser reconhecida pela IF como cumprimento de uma Hora Atividade prevista para o trabalho dos professores, conforme já mencionado. Dessa forma, a interação possui caráter institucional/oficial, uma vez que os fóruns foram organizados pela Secretaria de Estado da Educação com estes fins. Ou seja, ao mesmo tempo em que ocorre no espaço online, a abertura e o fechamento dos fóruns instigam um discurso mais planejado e direcionado.

Ainda sobre o direcionamento do discurso institucional/oficial da IF, há, em sua maioria, comentários mais voltados à indicação de conteúdos de leitura aos professores e não propriamente ao debate - característico de um fórum, como se pode observar nos excertos a seguir.

C3 - IF - "HQs e clássicos literários"

"A hora da estrela" (1985), de Suzana Amaral, pautou-se na obra homônima de Clarice Lispector. Confira algumas dicas pedagógicas em: http://www.portugues.seed.pr.gov.br/modules/video/showVideo.php?video=11971

C4 - IF - "HQs e clássicos literários"

Sugerimos a leitura do artigo que traz uma análise comparativa de "O Quinze", de Rachel de Queiroz, e a obra homônima de Jurandir Olieveira, "O quinze: da palavra à imagem". (Disponível em: http://www.educadores.diaadia.pr.gov.br/modules/mydownloads_01/visit.php?cid=44おlid=7065) 
Conforme já evidenciado, há uma exposição dos recursos disponíveis sobre autores, obras, trabalhos relacionados aos temas em pauta e que foram disponibilizados previamente na página do portal. Dessa forma, a IF indica materiais e conteúdos, porém a maior dificuldade evidenciada pelos professores está no âmbito teórico-metodológico. Traçando exemplos quanto ao discurso dos professores, estes, em sua maioria, estão atrelados no âmbito metodológico e voltados à dificuldade de adequar/trabalhar o tema em pauta em sala de aula.

Nos comentários a seguir, observamos professoras afirmando ter proximidade com o tema, considerando-o relevante para a sua prática, mas evidenciando alguns questionamentos no tocante ao modo de trabalhar o conteúdo. No entanto, em nenhuma dessas ocorrências há uma reação-resposta da IF, no sentido de sanar a dúvida do professor, e sim uma reação-resposta dos outros professores construindo um movimento de troca/ partilha de experiências entre os pares.

C5 - IF - "Internetês"

Sabemos que o Internetês é necessário visto que viabiliza a comunicação, tornando-a instantânea e ágil. C6 - Sabrina - "Internetês"

Gostaria de saber, como trabalhar na questão dos erros ortográficos que apresentam diante do uso constante da Internet, e como usar isso em benefício do aluno, já que é inevitável?

C7 - Josiane - "Internetês"

E não tem como combater, é uma luta inglória, portanto devemos usá-lo e tirar proveito dele.

C8 - Vilma - "Internetês"

Não vejo como problema, se o aluno tiver claro quando pode usar esse tipo de linguagem.

C9 - Vanuza - "Internetês"

Acho que na escola o internetês prejudica sim. Porém, seu uso na internet, é devido ao português contemporâneo, moderno... devemos cuidar para que isso não se torne hábito nas escolas.

C10 - Ana - "Internetês"

Não acho prejudicial, com a internet os alunos estão escrevendo mais do que nunca, basta mostrarmos a diferença de linguagem e como utilizá-las.

C11 - Paula - "Internetês"

Nossos professores tem muita dificuldade de corrigir os trabalhos e avaliações dos nossos alunos pois eles usam muito a linguagem internetês, o qual é a abreviação das palavras.

Nas interações analisadas, observamos que os professores, ao se posicionarem nos fóruns, relacionam os conteúdos de ensino e aprendizagem de LP às suas vivências no espaço escolar, por vezes concordando, revozeando e refutando entre si. Como podemos observar nos excertos, o enunciado disparador do debate foi produzido pela IF, que direciona o tópico afirmando que o "internetês" torna a comunicação ágil e rápida. Em seguida, Sabrina, em C6, questiona sobre como lidar com os "erros" ortográficos, isso 
porque, na sua visão, essas relações com termos abreviados não vão mudar e, por isso, pede ajuda sobre como lidar com essa recorrência. Logo após, em C7, há uma reação-resposta da professora Josiane, afirmando que não há como combater, ou seja, mais uma vez há aqui a acentuação na noção de erro ao enfatizar o termo "combater". Em C9, a professora Vanuza aponta para o uso, e diz que é preciso que o aluno saiba adequá-lo à situação comunicativa, no entanto, ressalta que é algo "prejudicial” e que deve haver um cuidado para que esse "tipo de linguagem" não chegue à escola. Em C10, a professora Ana evidencia um contradiscurso ao refutar as falas que avaliam negativamente o "internetês". A professora avalia que não houve prejuízo na língua, considerando que hoje as pessoas escrevem mais do que antes e frisa que é dever do professor orientar o aluno sobre o uso. Em C11, a professora Paula apresenta dificuldade didático-metodológica no que se refere ao modo de se trabalhar a correção das avaliações.

Em C12, a seguir, a IF retoma a discussão, evidenciando uma compreensão de língua como sendo dialógica, porém, tecendo um comentário breve, sem muita progressão ou resposta ao que vinha sendo discutido pelos professores acerca do trabalho metodológico no âmbito da sala de aula.

C12 - IF - "Internetês"

Professores, sabemos que a língua é viva e dinâmica e, como tal, não se mantém alheia às transformações culturais de uma sociedade.

C13 - IF- "Internetês"

Professor, você já encontrou o internetês nos textos produzidos por seus alunos? Como tratou do assunto?

Sendo assim, a IF assume, em C12, que a língua é viva e dinâmica, mas em C13 questiona se os professores já encontraram “internetês" nos textos dos alunos e como trataram do assunto, evidenciando assim certa incoerência. Essa indefinição e/ou não clareza quanto ao seu posicionamento em relação aos temas se mostra em alguns momentos. Os professores respondem ativamente: há os que leram os textos de apoio disponibilizados e concordam com a ideia enunciada pela IF de língua viva e passível de modificações, e há os que defendem uma língua padrão, que deve ser objeto de ensino e aprendizagem, e a "internetês" como algo a ser "combatido".

Adentrando em outros aspectos, quando o professor questiona, ao longo do debate, sobre onde pode ter acesso aos materiais, a IF aponta para os recursos disponibilizados pelas instituições públicas, sugerindo que tudo o que o professor necessita para trabalhar em sala de aula está ao seu alcance, respondendo aos questionamentos de forma vaga/ imprecisa, como na situação mais contextualizada que vemos a seguir. 
C14 - IF - "HQs e clássicos literários"

O quadrinho traz em si grande potencial comunicativo, apresentando uma união própria entre as linguagens verbal e não verbal.

C15 - Verônica - "HQs e clássicos literários"

Excelente para se trabalhar a linguagem verbal e não-verbal. Os alunos adoram leitura de $H Q$.

C16 - Maristela - "HQs e clássicos literários"

Sugiro um banco de tirinhas e HQs para consulta dos professores e até mesmo uma possibilidade demudarmos os textos nos balõezinhos...

C17 - Marcela "HQs e clássicos literários"

Ótima ideia, X acredito que eles terá mas participação e incentivo na leitura e produção.

C18 - Mikael - "HQs e clássicos literários"

AS escolas deve investir mais em HQs, adquirir mais exemplares.

C19 - José - "HQs e clássicos literários"

$\mathrm{Na}$ busca constante de contextualzação e intertextualização

C20 - Emanuelle - "HQs e clássicos literários"

Mas como ter acesso ao material????

C21 - IF - "HQs e clássicos literários"

$O$ acervo do PNBE enviado pelo MEC às escolas públicas contém vários livros com adaptações de obras literárias em HQ. Vale a pena conferir.

C22 - IF - "HQs e clássicos literários"

Que HQs adaptadas de clássicos literários você conece e com quais já trabalhou?

C23- Mara - "HQs e clássicos literários"

Tenho trabalhado com os alunos do $6^{\circ}$ ano Monteiro Lobato em HQs os alunos tem um aproveitamento maravilhoso da leitura.

A partir desse conjunto de comentários é possível observar que os professores compreendem a importância metodológica de se trabalhar com HQs e clássicos literários, mas alguns professores apontam para uma dificuldade referente aos materiais, sobre o acesso e a disponibilização, e a IF indica, por sua vez, materiais dos projetos governamentais. Logo após, há uma mudança no tópico pela IF, questionando sobre a experiência dos professores no trabalho com HQs (C22), ou seja, remetendo ao trabalho didático dos cursistas.

Na maioria das situações, a IF parece não dar conta de responder às discussões nos fóruns e os professores começam a dar suporte uns aos outros, como ocorre na sequência a seguir: os professores interagem 70 vezes entre si em um intervalo de uma fala da IF à outra, e essas falas indicam apenas a mudança de tópico nos debates.

C24 - IF - "Internetês"

Autores como Thurlow e Brown (2010) afirmam que o internauta deve dominar a norma padrão da sua língua, pois a recuperação de vogais suprimidas, a substituição de silabas por números e a leitura de termos homofônicos só pode ser feita por um internauta que tenha intuições linguísticas aguçadas. Vocês concordam com essa afirmação? 
Após 70 comentários sem outras considerações ou retorno sobre a fala dos professores, a IF retoma a palavra e muda o tópico. Isso acontece em um intervalo de quatro minutos, ou seja, na maioria das vezes a IF apenas cumpre esse papel na interação, o de alternar o tópico da discussão, como vemos no exemplo a seguir, em que novamente retorna à interação para mudar o tópico discutido.

C25 - IF - "Internetês"

colegas, de acordo com as Diretrizes Curriculares de Língua Portuguesa, "O aperfeiçoamento da escrita se faz a partir das experiências sociais tanto singular, quanto coletivamente vividas."

Já as interações entre os professores, por sua vez, são bem mais constantes. Os professores interagem com seus pares, seja refutando, concordando, revozeando etc. e trazem o aluno para o debate "seu grande outro", como vemos no comentário da professora Natália, C26, em seguida. A IF, não raras vezes, responde indicando um conteúdo disponível para responder ao professor, assumindo um tom mais conteudista, como em C27. Consequentemente, o "tom" da interação da IF, muitas vezes, acontece de forma mais técnica sobre o tema, dissociada da práxis dos professores.

C26 - Natália - "Adaptações cinematográficas"

Concordo com a $X$, gosto de utilizar os recursos cinamatográficos para ilustrar uma obra de arte. Pois os nosso alunos muitas vezes precisam de uma "ajudinha" para conseguir interpretar ou até mesmo descrever algumas obras (estilo de roupa, época, etc).

C27 - IF - "Adaptações cinematográficas"

acesse as páginas de Lingia Portuguesa e de Cinema do Portal Dia a Dia Educação. Lá você encontra inúmeras indicações para auxiliar no seu trabalho. Um abraço.

Em suma, no tocante ao horizonte temático-valorativo, a IF e os professores assumem posicionamentos valorativos diferentes. A IF planeja os seus posicionamentos previamente à realização das interações, cumprindo com as exigências oficiais sobre a realização da formação continuada online, sobretudo, no que se refere à proposição de temas nos fóruns. Como podemos observar nessas situações apontadas anteriormente, a IF repete os comentários feitos ao longo de toda a discussão, evidenciando assim que seu posicionamento se dá mais a partir de uma posição mais conteudista e monológica no desenvolvimento dos temas nos fóruns, sem que haja muito espaço para o debate direto com o professor ${ }^{8}$. Assim, acaba deixando uma lacuna quanto às necessidades teórico-metodológicas dos professores e não dando conta de responder às demandas naquele espaço

\footnotetext{
8 Há apenas uma ressalva quanto a essa afirmação. Dos três fóruns realizados, o fórum “Internetês" apresenta uma participação mais responsiva quanto à atuação da IF, dado o contexto de discussão recorrente sobre os ambientes online e pressupondo um posicionamento mais teórico voltado às concepções de língua.
} 
de formação. Em contrapartida, é nas interações entre os professores que se observa uma presença de reações-respostas mais evidentes como: a contrapalavra, a reação-resposta, a retomada dos temas, o compartilhamento de experiências práticas etc.

\section{CONSIDERAÇÕES FINAIS}

Neste texto, focalizamos o horizonte temático-valorativo de enunciados de fóruns online em um contexto de formação de professores de LP. Nas interações analisadas, observamos que a IF planeja e conduz a interação com a demanda oficial, porém com uma acentuação mais conteudista dos temas em pauta, bem como com uma valoração mais proeminente dos materiais disponibilizados e da demanda oficial, em detrimento aos posicionamentos dos professores advindos de seus saberes constituídos na prática educativa. Assim, o texto linkado assume o espaço de resposta-ativa da IF, frente a um questionamento do professor. Por outro lado, vale destacar que essa forma de interagir - responder a partir de links de outros textos - é uma prática discursiva própria da Web 2.0.

Sobre as vozes de autoria do professor, estas evidenciam um excedente de visão sobre a prática do "ser professor", uma vez que é na relação uns com os outros que os sujeitos trocam experiências e trazem o aluno para o debate como seu objeto de discurso. Os professores, assim, assumem posicionamentos autorais frente aos seus interlocutores e, para tanto, agenciam a sua vivência no espaço da aula. É possível aventar que essas falas, as que mobilizam suas experiências, foram constituídas nas vivências pregressas dos sujeitos, tanto em sua formação acadêmica, como nos conhecimentos construídos ao longo da carreira com outros colegas.

\section{REFERÊNCIAS}

BAKHTIN, M. M. Estética da criação verbal. Tradução de Paulo Bezerra. 4. ed. São Paulo: Martins Fontes, 2003 [1979].

BAKHTIN, M. M. Problemas da poética de Dostoiévski. Tradução, notas e prefácio de Paulo Bezerra. 4. ed. rev. e ampl. Rio de Janeiro: Forense Universitária, 2008 [1963].

BAKHTIN, M. M. Os gêneros do discurso. Tradução de Paulo Bezerra. São Paulo: Editora 34, 2016 [1953]).

BAKHTIN, M. M.; VOLOCHÍNOV, V. N. Marxismo e filosofia da linguagem. 12. ed. Tradução de Michel Lahud e Yara Frateschi Vieira. São Paulo: Editora Hucitec, 2006 [1929].

BARTON, D.; LEE, C. Linguagem online: textos e práticas digitais. Tradução de Milton Camargo Mota. 1. ed. São Paulo: Parábola Editorial, 2015. 
FURTADO, I. P. D. Portal ou Porteira? Os Professores e uma experiência de integração da Internet no Ensino Fundamental por meio de um Portal Educativo. 2004. $160 \mathrm{f}$. Dissertação (Mestrado em Educação). Programa de Pós-Graduação em Educação, Universidade Federal do Ceará, Fortaleza , 2004.

GATINHO, J. B. M. Sequências de atividades didáticas propostas por professores em formação continuada. In: SIGNORINI, I. (Org.). Gêneros catalisadores: letramento e formação do professor. São Paulo: Parábola Editorial, 2006. p. 143-156.

GATTI, B. A. Análise das políticas públicas para a formação continuada no Brasil, na última década. Revista Brasileira de Educação, Rio de Janeiro, v. 13, n. 37, p. 57-70, jan./ abr. 2008.

GONÇAlVES, A. V.; PETRONI, M. R. (Org.). Formação inicial e continuada de professores: o múltiplo e o complexo das práticas educativas. Dourados: Ed. UFGD, 2012.

RODRIGUES, R. H. Os gêneros do discurso na perspectiva dialógica da linguagem: a abordagem de Bakhtin. In: MEURER, J. L.; BONINI, A.; MOTTA-ROTH, D. Gêneros: teorias, métodos e debates. São Paulo: Parábola, 2005. p. 152-183.

ROHLINGDASILVA,N. Ogêneroentrevistapingue-pongue: reenunciação, enquadramento e valoração do discurso do outro. 2007. 237 f. Dissertação (Mestrado em Linguística). Programa de Pós-Graduação em Linguística, Universidade Federal de Santa Catarina, Florianópolis, 2007.

ROHLING DA SILVA, N. A atuação do professor de língua portuguesa discursivizada por licenciandos na Educação a Distância: o embate entre o discurso da tradição e o discurso teórico. 2012. 382 f. Tese (Doutorado em Linguística). - Programa de Pós-Graduação em Linguística, Universidade Federal de Santa Catarina, Florianópolis, 2012.

ROJO, R.H. R.Escol@ Conectada: os multiletramentos e as TICs. São Paulo: Parábola, 2013.

TARDIF, L. M. Saberes docentes e formação profissional. Petrópolis: Vozes, 2002.

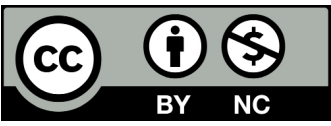

Data de submissão: 28/01/2020

Data de aceite: 06/05/2020 